\title{
Chronic Continuous or Intermittent Infusion of Cocaine Differentially Alter the Concentration of Neurotensin-like Immunoreactivity in Specific Rat Brain Regions
}

Scott T. Cain, Ph.D., Daniel Griff, B.S., Catherine M. Joyner, B.S., Everett H. Ellinwood, M.D., and Charles B. Nemeroff, M.D., Ph.D.

Neurotensin (NT) is an endogenous brain tridecapeptide that exhibits selective anatomic and neurochemical interactions with rat brain dopaminergic systems. Because modulation of dopaminergic neurotransmission may underlie many of the behavioral properties of cocaine, the effects of both acute and chronic administration of cocaine on the concentration of NT-like immunoreactivity (NT-LI) in specific brain regions was determined. Adult male rats were treated with cocaine for 14 days at a dose of $40 \mathrm{mg} / \mathrm{kg} /$ day $(0.118 \mathrm{mmoles} / \mathrm{kg} /$ day $)$ administered as either 1 subcutaneous injection per day, or infused continuously using subcutaneously implanted minipumps. Neurotensin-like immunoreactivity in specific brain regions was then measured 24 hours or 8 days following drug administration. After 24 hours of withdrawal from daily subcutaneous injection, the concentration of NT-LI was significantly increased in the substantia nigra (SN) and frontal cortex. After 24 hours of withdrawal from continuous infusion with cocaine, NT-LI was increased only in the SN. After 8 days of withdrawal, NT-LI was increased in the SN of rats treated with daily subcutaneous injections of cocaine, but not in the group treated with continuous infusion. Twenty-four hours following a single acute injection of $40 \mathrm{mg} / \mathrm{kg}$ of cocaine, NT-LI was increased in the SN and nucleus accumbens. These results provide evidence consistent with a neuroanatomically selective involvement of NT systems in the behavioral and/or addictive properties of cocaine. [Neuropsychopharmacology 8:259-265, 1993]
KEY WORDS: Neurotensin; Cocaine; Radioimmunoassay; Substantia nigra; Nucleus accumbens; Frontal cortex

The potential involvement of central nervous system (CNS) dopaminergic (DAergic) systems in the be-

From the Departments of Psychiatry (STC, DG, CMJ, EHE, CBN) and Pharmacology (EHE, CBN), Duke University Medical Center, Durham, North Carolina.

Address correspondence to: Scott T. Cain, Ph.D., Department of Psychiatry, Duke University Medical Center, Box 3859, Durham, North Carolina 27710.

Received January 21, 1992; revised August 21, 1992; accepted September 22, 1992.

Current address for Charles B. Nemeroff: Department of Psychiatry, Emory University School of Medicine, Atlanta, Georgia. havioral effects of the psychostimulant, cocaine, has been intensively investigated (Kleven et al. 1990; $\mathrm{Ng}$ et al. 1991; Peris et al. 1990). However, it is only recently that attention has been directed to possible cocaineinduced alterations in neuropeptide-containing systems. For example, chronic cocaine administration results in increased concentrations of dynorphin in the striatum and substantia nigra (SN) (Sivam 1989), but decreased concentrations of neuropeptide $Y$ and its messenger ribonucleic acid in the medial prefrontal cortex (Wahlestedt et al. 1991). In addition, somatostatin receptors are decreased in density in the hippocampus and olfactory bulb of rats treated chronically with cocaine (Rodriguez-Sanchez and Arilla 1990), as are recep- 
tors for corticotropin-releasing factor in terminal areas of the mesolimbic/mesocortical DA pathway (Goeders et al. 1990).

Our laboratory sought to test the hypothesis that neurotensin (NT), an endogenous brain tridecapeptide that exhibits a number of well-documented, selective interactions with DAergic systems within the mammalian CNS (Nemeroff and Cain 1985), may mediate, at least in part, the behavioral effects of cocaine. In previous studies, we demonstrated that intracisternal injection of NT attenuated the locomotor hyperactivity induced by a single acute injection of cocaine (Nemeroff et al. 1983). More recently, chronic cocaine treatment has been reported to increase NT concentrations in the striatum and $\mathrm{SN}$; however, following a single dose of cocaine, NT increases were observed only in the SN (Hanson et al. 1989). These increases in NT concentration were attenuated by blockade of $\mathrm{N}$-methyl-Daspartate receptors, suggesting glutaminergic mediation of cocaine-induced alterations in NT concentrations (Johnson et al. 1991). In addition, 10 days following chronic cocaine administration, NT binding was increased in the SN compacta and prefrontal cortex, but decreased in the ventral tegmental area (VTA) (Pilotte et al. 1991). Therefore, in view of the evidence implicating CNS NT systems as an important component of the neurochemical response to cocaine, we evaluated alterations in NT concentrations in specific rat brain regions at both 24 hours and 8 days following 14 days of continuous or intermittent exposure to cocaine.

The two methods of chronic cocaine administration have been shown by both our group (King et al. 1992) and others (Reith et al. 1987) to result in different residual behavioral profiles. Continuous exposure to cocaine induces behavioral tolerance whereas intermittent administration yields behavioral sensitization. We believe that the continuous-infusion paradigm represents an animal model of "binge-like" cocaine abuse in which chronic users maintain a sustained plasma level of cocaine over extended periods by readministering the drug every $1 / 2$ hour or less for days (Gawin and Ellinwood 1988; Gawin 1991). In contrast, the intermittentdosing paradigm models the recreational user in whom sensitization develops to the reinforcing effect of the drug, a necessary step in the development of heavy abuse. Thus, the current experiments represent an examination of the possible role of CNS NT systems in the neurochemical mechanisms underlying chronic cocaine-induced behavioral tolerance and sensitization.

\section{METHODS}

\section{Animals}

Adult male Sprague-Dawley rats weighing between 100 and $125 \mathrm{~g}$ (Charles River Laboratories) were acclimated to the vivarium for 1 week prior to treatment. They were housed in pairs under controlled conditions of temperature and humidity and given free access to laboratory chow and water.

\section{Drug and Minipump Preparation}

Cocaine $\mathrm{HCl}$ (generously provided by National Institute on Drug Abuse) was dissolved in $0.9 \%$ sterile saline, and used for either injection or minipump preparation. Alzet osmotic minipumps (model 2ML2, Alza Corporation) were filled with either $2 \mathrm{ml}$ of $100 \mathrm{mg} / \mathrm{ml}$ (0.294 mmoles/ml) of cocaine $\mathrm{HCl}$ or saline. The infusion rate was $5 \mu \mathrm{l} / \mathrm{hr}$ resulting in an overall average dose of $40 \mathrm{mg} / \mathrm{kg} /$ day $(0.118 \mathrm{mmoles} / \mathrm{kg} /$ day $)$.

\section{Surgery}

The animals were shaved and injected locally with lidocaine at the dorsal midline incision site prior to the administration of methoxyflurane inhalation anesthesia. A 2-cm midline incision was made and the minipump inserted into a subcutaneous pocket with the portal to. ward the head. The wound was closed with metal autoclips. On day 14 , selected pumps were surgically removed and the residual amount of cocaine determined. Results were consistent with both the expected infusion rate and with stability of the cocaine solution under conditions of physiologic $\mathrm{pH}$ and temperature for the 14-day treatment period.

\section{Cocaine Treatment}

On day 1 of treatment, animals were divided into groups receiving (1) implants of cocaine-containing minipumps delivering an average of $40 \mathrm{mg} / \mathrm{kg}$ of $\mathrm{co}$ caine per day; (2) a once-daily subcutaneous injection of $40 \mathrm{mg} / \mathrm{kg}$ of cocaine; or (3) once-daily subcutaneous injections of saline or implants of saline-containing minipumps. In our initial experiments, both salineinjection and saline-minipump groups were used as controls. However, because there were no statistically significant differences in the NT-LI concentrationin any brain region between the two types of vehicle treatments, in subsequent experiments we used only the vehicle-injection group. Treatment was continued for 14 days. At either 24 hours or 8 days following the final treatment with cocaine or vehicle, the rats were killed by decapitation and brains rapidly removed and frozen. From the frozen brains, the frontal cortex (FC), caudate nucleus $(\mathrm{CN})$, nucleus accumbens (NA), SN, and VTA were dissected. For the dissections, frozen brains were placed ventral side up in a brain matrix and anchored using a razor blade $1 \mathrm{~mm}$ behind the optic chiasm. The brain was stabilized in the matrix using a razor blade through the FC and successive 1-mm sec- 
tions were made until the cerebellum was reached. The FC was cut out of the first slice, the NA was dissected from the section including the anterior commissure, and the $\mathrm{CN}$ was cut from the slice succeeding the one containing the NA. The last slice normally contained the VTA and SN.

\section{Neurotensin Radioimmunoassay}

Frozen brain tissue was extracted by sonication in ice cold $1 \mathrm{~N} \mathrm{HCl}$ in polypropylene centrifuge tubes and centrifuged at $10,000 \times g$ for 15 minutes at $4^{\circ} \mathrm{C}$. Duplicate aliquots of supernatant in borosilicate glass tubes were lyophilized, reconstituted in phosphate-buffered saline (PBS [0.01 mol/L NaH $\mathrm{POO}_{4}, 0.15 \mathrm{~mol} / \mathrm{L} \mathrm{NaCl}, 0.01 \%$ sodium azide, $0.01 \mathrm{~mol} / \mathrm{L}$ ethylenediaminetetraacetic acid, $0.05 \%$ Triton $\mathrm{X}-100$, and $0.1 \%$ gelatin, $\mathrm{pH} 7.6]$ ), and assayed for NT-like immunoreactivity (NT-LI) using a sensitive and specific radioimmunoassay according to previously described methods (Bissette et al. 1984). Synthetic $\mathrm{NT}_{1-13}$ was used as standard and was iodinated by the chloramine-T method (Hunter and Greenwood 1962). Our NT antiserum recognizes the 6-8 midportion of intact NT and was used at a final dilution of 1:8000. Goat anti-rabbit antiserum (Arnel Products, New York, NY) was used as second antibody.

Precipitates were dissolved in $1 \mathrm{~N} \mathrm{NaOH}$ and assayed for protein concentration according to the method of Lowry et al. (1951) using bovine serum albumin as standard. Neurotensin concentrations were expressed as picograms NT-LI per milligram protein.

\section{Statistics}

Data were analyzed for statistical significance using oneway analysis of variance followed by Scheffé's (1953) test to compare differences between individual means. Significance was assumed if $p<0.05$.

\section{RESULTS}

The concentration of NT-LI in specific brain regions was measured 24 hours following a single subcutaneous injection of vehicle or $40 \mathrm{mg} / \mathrm{kg}$ of cocaine. Following cocaine injection, NT-LI was significantly increased in the $\mathrm{NA}(\uparrow 94 \% \pm 9.1 \%$, Fig. $1 \mathrm{a})$ and SN $(\uparrow 44 \% \pm 8.3 \%$, Fig. 1b). In contrast, acute injection with cocaine did not significantly alter the concentration of NT-LI in the FC (Fig. 1c), CN (Fig. 1d), or VTA (Fig. 1e).

Rats were treated with vehicle or $40 \mathrm{mg} / \mathrm{kg}$ of cocaine (subcutaneous injection or continuous infusion) for 14days, and the concentration of NT-LI was determined after 24 hours and 8 days of withdrawal. In contrast to the effects of a singleinjection of cocaine, NT-LI was not altered in the NA after either period of withdrawal (Fig. 1a). However, in the SN, NT-LI was signifcantly increased both 24 hours $(\uparrow 61 \% \pm 8.6 \%)$ and 8 days $(\uparrow 26 \% \pm 8.6)$ following 14 daily injections of cocaine. In rats implanted with cocaine-containing minipumps, NT-LI was significantly increased in the SN after 24 hours ( $\$ 35 \% \pm 6.9 \%)$, but not 8 days of withdrawal (Fig. $1 b)$. The increase in SN NT-LI was significantly larger in the cocaine-injected group than in the minipump group at both the 24-hour and 8-day time points.

In the FC, NT-LI was significantly increased, ( $\$ 33 \%$ $\pm 7.9 \%) 24$ hours following withdrawal from 14 days of cocaine injections. This increase was no longer present after 8 days of withdrawal and, furthermore, NT$\mathrm{LI}$ in the FC was not altered at either time point after continuous treatment with cocaine via implanted minipump (Fig. 1c). In the CN, although NT-LI was not statistically altered at 24 hours or 8 days of withdrawal following either daily injections or minipump infusion (Fig. 1d), there was a clear trend toward an increase in CN NT-LI in rats treated with single or chronic injections of cocaine. In the VTA, chronic cocaine treatment had no effect on the concentration of NT-LI at 24 hours or 8 days of withdrawal using either injection paradigm (Fig. 1e).

\section{DISCUSSION}

We have shown that both acute and chronic exposure to cocaine induce time-dependent, anatomically selective alterations in the concentration of NT in specific brain regions. Confirming an earlier report (Hanson et al. 1989), we observed that NT systems within the SN are exquisitely sensitive to acute and chronic cocaine injections, with a significant increase in NT concentration that persists for at least 8 days after 14 days of treatment. It is noteworthy, however, that SN NT was increased after 24 hours, but not after 8 days of withdrawal from 14 days of continuous cocaine exposure, and that even at 24 hours, the injection group had significantly greater SN-NT concentrations than the minipumptreated group. Within the SN, NT has been localized to both axon terminals and neuronal perikarya (Hökfelt et al. 1984; Jennes et al. 1982), with a high density of NT receptors localized on DA perikarya and dendrites (Palacios et al. 1982; Szigethy and Beaudet 1989). This anatomic distribution of NT content and receptors is consistent with the ability of the peptide to exert an excitatory effect on SN DA neurons (Pinnock 1985).

The large increase in NA-NT concentration following an acute injection of cocaine was not observed after either mode of chronic cocaine treatment, indicating that the basal activity of NT systems within the NA develop a tolerance to repeated exposure to the drug. Because there is a great deal of evidence implicating 

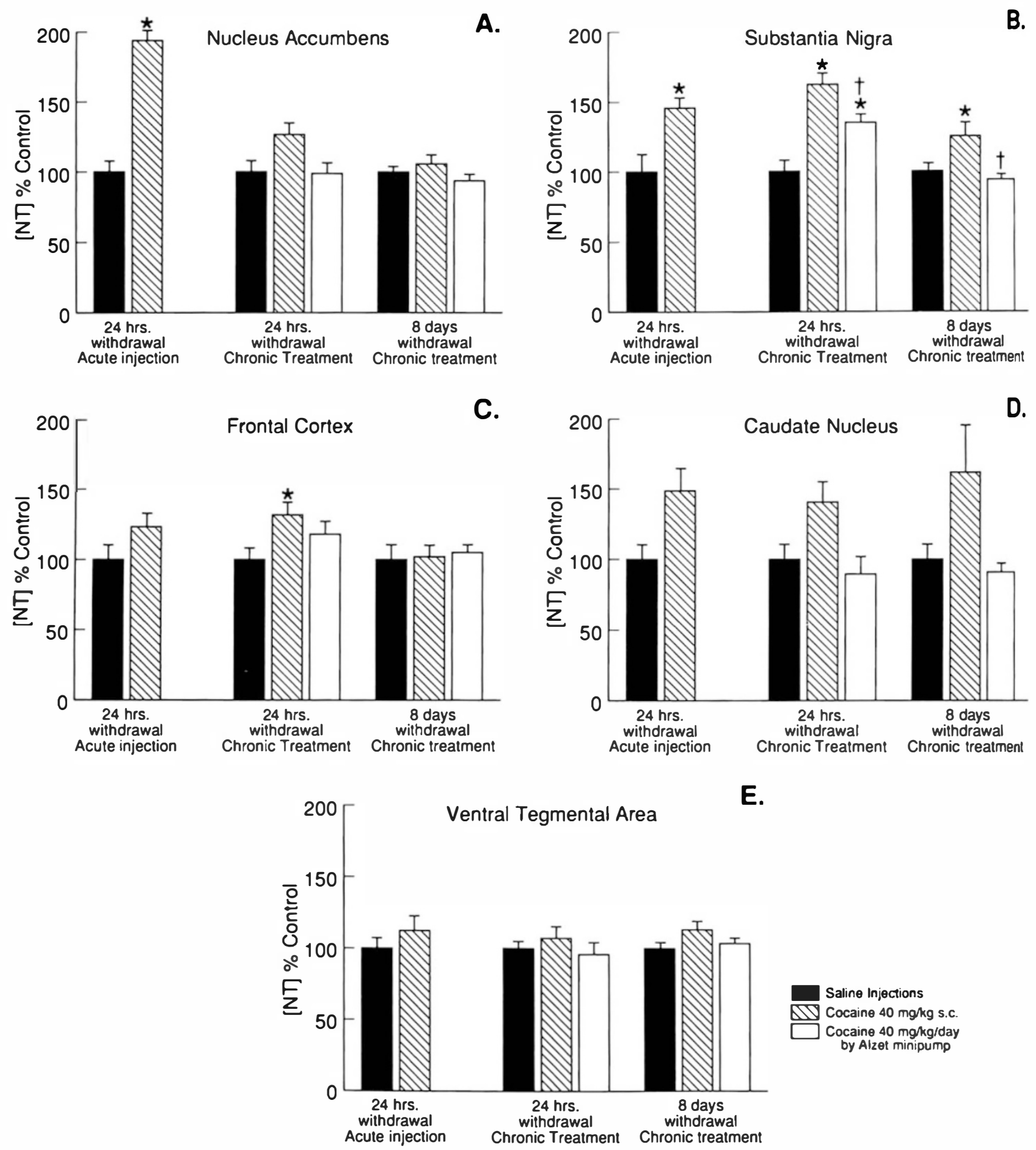

Figure 1. Rats were sacrificed 24 hours following a single subcutaneous (SC) injection of $40 \mathrm{mg} / \mathrm{kg}$ cocaine or vehicle (n $=6$ to 8 ) and 24 hours and 8 days after 14 days of SC vehicle injections, once-daily $40 \mathrm{mg} / \mathrm{kg}$ SC cocaine injections or 14 days of $40 \mathrm{mg} / \mathrm{kg} /$ day continuous infusion of cocaine using minipumps implanted subcutaneously $(n=13$ to 16$)$. After the designated period of withdrawal, the rats were killed by decapitation and the brain removed and rapidly frozen. The NA (Fig. 1a), SN (Fig. 1b), FC (Fig. 1c), CN (Fig. 1d), and VTA (Fig. 1e) were dissected from the frozen brain. Samples were extracted in $1 \mathrm{~N} \mathrm{HCl}$ and the radioimmunoassay for NT performed as described in Methods. Two separate experiments were run for both the 24-hour and 8-day withdrawal groups. All brain regions within a particular experiment were assayed simultaneously. Results from both experiments were expressed as percent of control NT-LI and combined for statistical analysis. Ab. solute amounts of NT-LI in picogram per milligram protein for each of the saline control groups are provided below.

Acute injection and 24-hour withdrawal (experiment 1). NA: $239.9 \pm 28.6$; SN: $392 \pm 47$; FC: $63.6 \pm 5.9$; CN: 111.3 \pm 11.1 ; and VTA: $800.6 \pm 60.9$. 
NA-DA systems in the physiologic response to cocaine (Delfs et al. 1990; Henry et al. 1989) as well as evidence linking intra-NA NT to the modulation of DA-mediated behaviors (Kalivas et al. 1984), it will be of interest to determine the significance of this apparent tolerance of theNA-NT system that develops during chronic cocaine exposure. In contrast to NA NT, there is an apparent sensitization of FC NT to chronic cocaine injections, but not to continuous infusion. Rats will self-administer cocaine into the medial prefrontal cortex (Goeders and Smith 1983); a phenomenon that is dependent uponintactDAergic innervation of the cortex (Goeders and Smith 1986). Although information concerning the functional significance of frontal cortical NT is sketchy, a mixed mesocortical NT-DA pathway in the rodent has been reported (Seroogy et al. 1988; Studler et al. 1988) and NT and DA are coreleased upon afferent stimulation (Bean et al. 1989; Bean and Roth 1991). Neither acute nor chronic treatment with cocaine significantly altered the NT content of $\mathrm{CN}$ or VTA. The lack of cocaine-induced NT concentration changes in the $\mathrm{CN}$ is somewhat discrepant with the report of Hanson et al. (1989) in which an increase in striatalNT content up to 24 hours following multiple doses of cocaine was reported. However, perusal of our results (Fig. 1d) indicates that there was a clear trend toward an increase in CN NT following both acute and chronic injections of cocaine. We noted that Hanson et al. (1989) also observed significant experimental variability in striatal NT content 24 hours following an acute intraperitoneal injection of $30 \mathrm{mg} / \mathrm{kg}$ cocaine. A possible explanation for the observed treatment-induced variability in NT content is the neurochemical heterogeneity of NT within the basal ganglia. For example, in the cat, NT is enriched in the striosomal compartment of the striatum (Goedert et al. 1983, 1984). Thus, to reliably observe cocaine-induced changes in striatal NT content, it may be necessary to evaluate the response of NT subsystems within this brain region.

It is important to recognize that the two chronic cocaine-treatment protocols yield opposite behavioral profiles. Daily injections result in behavioral sensitization, whereas, in contrast, continuous infusion induces behavioral tolerance to a subsequent challenge dose of cocaine (King et al. 1992; Reith et al. 1987). It is possible that behavioral and neurochemical differentiation be- tween the intermittent- and continuous-treatment paradigms results from differential rates of cocaine metabolism following the challenge injection. However, although the rate of cocaine metabolism was not determined in our experiments, Reith et al. (1987) monitored plasma and brain levels of cocaine and a metabolite, benzoylecgonine, 12 minutes after a challenge dose of cocaine in their sensitized and tolerant animals, but could discern no difference between the groups. An alternative explanation for the observed differentiation between continuous and intermittent paradigms is that the behavioral and neurochemical sequelae are the reflection of a low (continuous) versus high (intermittent) dose-response effect. Two points must be addressed in this regard. First, the animals undergoing continuous administration are clearly receiving a pharmacologically active dose of cocaine. This is evidenced by the development of behavioral tolerance in rats treated identically to those used in the experiments described in this report (King et al. 1992). Second, the majority of reports evaluating the effects of low-dose (10 to $15 \mathrm{mg} / \mathrm{kg}$ ) intermittent cocaine injection have noted behavioral sensitization in the injected animals (e.g., Segal and Kuczenski 1992), indicating that the temporal basis of the treatmentregimen is a critical factor in the development of tolerance or sensitization. Therefore, although it is still not possible to definitively conclude that the NT alterations we observed were unrelated to a dose-response phenomenon, we believe it likely that continuous versus intermittent exposure to cocaine engenders separable neurochemical states that mediate the opposing behavioral responses.

In summary, our findings are consistent with the notion that cocaine-induced changes in CNS-NT systems may underlie, at least in part, the pronounced behavioral sensitization/tolerance effects of cocaine. We have shown that the method of cocaine exposure selectively alters NT concentration within particular DA cell body and terminal regions. The differential responsiveness of nigrostriatal NT and mesolimbic NT is particularly interesting. To further evaluate the behavioral and functional significance of cocaine-induced alterations in NT neurobiology, it will be critical to refine the anatomic and neurochemical analysis of the NT response by analyzing cocaine-induced changes in NT gene expression as well as NT receptor function and expression.

\footnotetext{
Figure 1. (Continued)

Twenty-four-hour withdrawal (experiment 2). NA: $449 \pm 77$; SN: $480 \pm 28 ;$ FC: $67 \pm$ 5.8; CN: $130 \pm 23.2$; and VTA: $791 \pm 129$.

Eight-day withdrawal (experiment A). NA: $318.9 \pm 15.2 ; \mathrm{SN}: 489.5 \pm 36$; FC: $80.2 \pm 10.9 ; \mathrm{CN}: 63.3 \pm 10.2$; and VTA: $1121.6 \pm 98.3$.

Eight-day withdrawal (experiment B). NA: $232.8 \pm 18.6$; SN: $338.4 \pm 24 ;$ FC: $86.6 \pm 12$; CN: $67 \pm 7.9$; and VTA: 872.6 \pm 67.3 .

${ }^{\star} p<0.05$ relative to control; ${ }^{\dagger} p<0.05$ cocaine injection versus cocaine minipump.
} 


\section{ACKNOWLEDGMENTS}

This research was supported by National Institute on Drug Abuse Grant DA-05303 and National Institutes of Mental Health Grant MH-39415.

\section{REFERENCES}

Bean AJ, Roth RH (1991): Extracellular dopamine and neurotensin in rat prefrontal cortex in vivo: Effects of median forebrain bundle stimulation frequency, stimulation pattern and dopamine autoreceptors. J Neurosci 11:26942702

Bean AJ, During MJ, Roth RH (1989): Stimulation-induced release of coexistent transmitters in the prefrontal cortex: An in vivo microdialysis study of dopamine and neurotensin release. J Neurochem 53:655-657

Bissette G, Richardson C, Kizer JS, Nemeroff CB (1984): Ontogeny of brain neurotensin in the rat: a radioimmunoassay study. J Neurochem 43:283-287

Delfs JM, Schreiber L, Kelley AE (1990): Microinjection of cocaine into the nucleus accumbens elicits locomotor activation in the rat. J Neurosci 10:303-310

Gawin FH (1991): Cocaine addiction: Psychology and neurophysiology. Science 251:1580-1586

Gawin FH, Ellinwood EH Jr (1988): Cocaine and other stimulants: Actions, abuse and treatment. N Engl J Med 318:1173-1182

Goeders NE, Smith JE (1983): Cortical dopaminergic involvement in cocaine reinforcement. Science 221:773-775

Goeders NE, Smith JE (1986): Reinforcing properties of cocaine in the medial prefrontal cortex: primary action on presynaptic dopaminergic terminals. Pharmacol Biochem Behav 25:191-199

Goeders NE, Bienvenu OJ, De Souza EB (1990): Chronic cocaine administration alters corticotropin-releasing factor receptors in rat brain. Brain Res 531:322-328

Goedert M, Mantyh PW, Hunt SP, Emson PC (1983): Mosaic distribution of neurotensin-like immunoreactivity in the cat striatum. Brain Res 274:176-179

Goedert M, Mantyh PW, Emson PC, Hunt SP (1984): Inverse relationship between neurotensin receptors and neurotensin-like immunoreactivity in cat striatum. Nature 307:543-546

Hanson GR, Smiley P, Johnson M, Letter A, Bush L, Gibb JW (1989): Response by the neurotensin systems of the basal ganglia to cocaine treatment. Eur J Pharmacol $160: 23-30$

Henry DJ, Greene MA, White FJ (1989): Electrophysiological effects of cocaine in the mesoaccumbens dopamine system: Repeated administration. J Pharmacol Exp Ther 251:833-839

Hökfelt T, Everitt BJ, Theodorsson-Norheim E, Goldstein M (1984): Occurrence of neurotensin-like immunoreactivity in subpopulations of hypothalamic, mesencephalic, and medullary catecholamine neurons. J Comp Neurol 222:543-549

Hunter WM, Greenwood FC (1962): Preparation of iodine131 labelled human growth hormone of high specific activity. Nature 194:495-496
Jennes L, Stumpf WE, Kalivas PW (1982): Neurotensin Topographical distribution in rat brain by immunohistochemistry. J Comp Neurol 210:211-224

Johnson M, Bush LG, Gibb JW, Hanson GR (1991): Role of $\mathrm{N}$-methyl-D-aspartate (NMDA) receptors in the response of extrapyramidal neurotensin and dynorphin A systems to cocaine and GBR 12909. Biochem Pharmacol 41: 649-652

Kalivas PW, Nemeroff CB, Prange AJ Jr (1984): Neurotensin microinjection into the nucleus accumbens antagonizes dopamine-induced increase in locomotion and rearing. Neuroscience 11:919-930

King GR, Joyner C, Lee T, Kuhn C, Ellinwood HE (1992): Intermittent and continuous cocaine administration: Residual behavioral states during withdrawal. Pharmacol Biochem Behav 43:243-248

Kleven MS, Perry BD, Woolverton WL, Seiden LS (1990): Effects of repeated injections of cocaine on $D_{1}$ and $D_{2}$ dopamine receptors in rat brain. Brain Res 532:265-270

Lowry OH, Rosebrough NJ, Farr AL, Randall PJ (1951): Protein measurement with the Folin phenol reagent. J Biol Chem 193:265-275

Nemeroff CB, Cain ST (1985): Neurotensin-dopamine interactions in the CNS. Trends Pharmacol Sci 6:201-205

Nemeroff CB, Luttinger D, Hernandez DE, Mailman RB, Mason GA, Davis SD, Widerlov E, Frye GD, Kilts CD, Beaumont K, Breese GR, Prange AJ Jr (1983): Interactions of neurotensin with brain dopamine systems: Biochemical and behavioral studies. J Pharmacol Exp Ther 225:337-345

Ng JP, Hubert GW, Justice JB Jr (1991): Increased stimulated release and uptake of dopamine in nucleus accumbens after repeated cocaine administration as measured by in vivo voltammetry. J Neurochem 56:1485-1492

Palacios JM, Kuhar MJ (1981): Neurotensin receptors are lo. cated on dopamine-containing neurons in rat midbrain. Nature 294:584-589

Peris J, Boyson SJ, Cass WA, Curella P, Dwoskin LP, Larson G, Lin L-H, Yasuda RP, Zahniser NR (1990): Persistence of neurochemical changes in dopamine systems after repeated cocaine administration. J Pharmacol Exp Ther 253:38-44

Pilotte NS, Mitchell WM, Sharpe LG, De Souza EB, Dax EM (1991): Chronic cocaine administration and withdrawa of cocaine modify neurotensin binding in rat brain. Synapse 9:111-120

Pinnock RD (1985): Neurotensin depolarizes substantia nigr dopamine neurones. Brain Res 338:151-154

Quirion R, Chiueh CC, Everist HE, Pert A (1985): Compara. tive localization of neurotensin receptors on nigrostriatal and mesolimbic dopaminergic terminals. Brain Res 327:385-389

Reith MEA, Benuck M, Lajtha A (1987): Cocaine disposition in the brain after continuous or intermittent treatmen and locomotor stimulation in mice. J Pharmacol Exp Ther 243:281-287

Rodriguez-Sanchez MN, Arilla E (1990): Effects of acute and chronic cocaine administration on somatostatin level and binding in the rat brain. Neuropeptides 16:1-7

Segal DS, Kuczenski R (1992): Repeated cocaine administa tion induces behavioral sensitization and corresponding 
decreased extracellular dopamine responses in caudate and accumbens. Brain Res 577:351-355

Seroogy K, Ceccatelli S, Schalling M, Hokfelt T, Frey P, Walsh J, Dockray G, Brown J, Buchan A, Goldstein M (1988): A subpopulation of dopaminergic neurons in rat ventral mesencephalon contains both neurotensin and cholecystokinin. Brain Res 455:88-98

Scheffé H (1953): A method for judging all contrasts in the analysis of variance. Biometrika 40:87-104

Sivam SP (1989): Cocaine selectively increases striatonigral dynorphin levels by a dopaminergic mechanism. J Pharmacol Exp Ther 250:818-824
Studler JM, Kitabgi P, Tramu G, Herve D, Glowinski J, Tassin JP (1988): Extensive co-localization of neurotensin with dopamine in rat mesocortico-frontal dopaminergic neurons. Neuropeptides 11:95-100

Szigethy E, Beaudet A (1989): Correspondence between high affinity ${ }^{125}$ I-neurotensin binding sites and dopaminergic neurons in the rat substantia nigra and ventral tegmental area: A combined radioautographic and immunohistochemical light microscopic study. J Comp Neurol 279: 128-137

Wahlestedt C, Karoum F, Jaskiw G, Wyatt RJ, Larhammar D, Ekman R, Reis DJ (1991): Cocaine-induced reduction of brain neuropeptide $Y$ synthesis dependent on medial prefrontal cortex. Proc Natl Acad Sci USA 88:2078-2082 